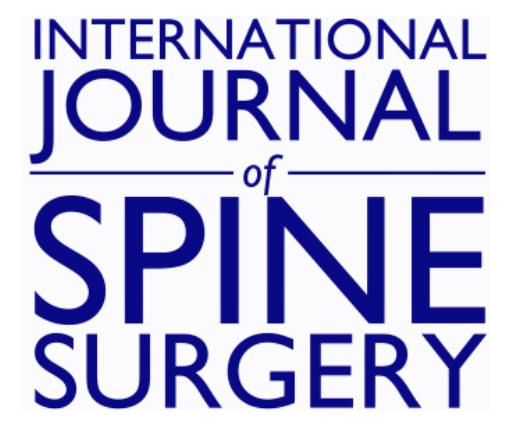

\title{
Remote Cervical Pseudomeningocele Following Anterior Cervical Corpectomy and Fusion: Report of a Case and Review of the Literature
}

Abolfazl Rahimizadeh, Housain Soufiani and Shaghayegh Rahimizadeh

Int J Spine Surg 2016, 10 ()

doi: https://doi.org/10.14444/3036

http://ijssurgery.com/content/10/36

This information is current as of April 26, 2023.

Email Alerts Receive free email-alerts when new articles cite this article. Sign up at:

http://ijssurgery.com/alerts

The International Journal of ShingeSurgerih 2397 Waterbury Circle, Suite 1,

Aurora, IL 60504, Phone: +1-630-375-1432

(C) 2016 ISASS. All Rights Reserved. 


\section{Remote Cervical Pseudomeningocele Following Anterior Cervical Corpectomy and Fusion: Report of a Case and Review of the Literature}

Abolfazl Rahimizadeh, MD, ${ }^{1}$ Housain Soufiani, MD, ${ }^{1}$ Shaghayegh Rahimizadeh ${ }^{2}$

${ }_{1}^{1}$ Department of Neurospinal Surgery, Pars Advanced 2Minimally Invasive Manners Research Center, Pars Hospital, Tehran, Iran

\section{Abstract}

Iatrogenic cervical pseudomeningocele is a rare event and majority are located posteriorly as a delayed complication of inadvertent dural tear after decompressive laminectomy. However, iatrogenic anterior cervical pseudomeningocele subsequent to discectomy or corpectomy is a rare pathology. The time necessary for formation of pseudomeningocele varies and depend on the width of the dural tear and the flow of cerebrospinal fluid leakage. Large tears with high CSF flow usually result in early collection of the cerebrospinal fluid in anterior compartment of the neck designated acute pseudomeningoceles. Micro-tears of dura mater, with low flow of cerebrospinal fluid may lead to late formation of a pseudomeningocele known as chronic ones.

Herein a 49- year-old woman in whom cervical pseudomeningocele appeared clinically as a mass on the anterior aspect of the neck, six months after anterior cervical corpectomy for cervical spondylotic myelopathy is presented. Otherwise, she was neurologically stable. Cystoperitoneal shunt was proposed which she refused. Surprisingly, at 2-year follow-up, the cyst had remained of the same size. To the best of our knowledge, this is the first example of post-operative chronic cervical pseudomeningocele in the literature, the event that might propose the self-limited natural course of this rare pathology in chronic cases.

KEYWORDS: ANTERIOR CERVICAL DISCECTOMY FUSION (ACDF), ANTERIOR CERVICAL CORPECTOMY FUSION (ACCF), CERVICAL PSEUDOMENINGOCELE, COMPLICATION, CYSTOPERITONEAL SHUNT

VOLUME 10 ARTICLE 36 DOI: 10.14444/3036

\section{Introduction}

Iatrogenic spinal meningocele develops as a consequence of an incidental durotomy or unrepairable dural tear and is an abnormal encapsulated collection of cerebrospinal fluid (CSF) communicating with the subarachnoid space. ${ }^{1-3}$

In an spinal surgery, unnoticed dural tear with intact arachnoid, via a ball valve mechanism a true cyst lined with arachnoid might develop. This type of iatrogenic cyst is called true meningocele where surrounding connective tissue might reinforce the arachnoid capsule over time.$^{1-3}$ Unrepaired small dural tear with concomitant arachnoid breach during a spinal surgery result in one way CSF flow and its accumulation in extradural region. Abnormal connective tissue reaction of surrounding the CSF collection leads to formation of a capsule lined by a fibrous tissue and ultimately a pseudocyst, so-called pseudomeningocele. ${ }^{1-3}$ In long standing cases, the fi- brous wall of the cyst might undergo ossification. ${ }^{3}$

Anterior spinal meningoceles involving the cervical spine are rare and have been almost always pseudomeningoceles. Cervical pseudomeningoceles are mostly located posteriorly and develop as the result of dural tear during laminectomy. ${ }^{4-10} \mathrm{But}$, in rare occasions, iatrogenic cervical pseudomeningoceles may occur after anterior cervical procedures mainly after ACCF rather than ACDF as a consequence of an inadvertent tear of the dura mater and pia arachnoid breach or a lack of closure of the dural tear with resultant CSF leakage into the anterior compartment of the neck. ${ }^{11-17}$

A chronic case which is the consequence of microdural tear, a pseudomeningocele develops from a month and later after surgery where time permits the surrounding tissue to react with formation of fibrous capsule around the CSF collection. The most striking, clinical feature of a chronic one might be only a 
unilateral soft palpable mass seen on the anterior aspect of the neck.

Cervical pseudomeningocele after anterior cervical discectomy fusion (ACDF) and corpectomy fusion (ACCF) for myelopathy with associated tear of dura mater was first documented in the English by Bertalnaffy and Eggert. ${ }^{11}$ These authors in their large series of 450 patients with anterior cervical discectomy, encountered one case with CSF fistula $(0.2 \%)$ who consequently got meningitis, but survived. ${ }^{11}$ Thereafter, Horowitz et al in 1990 described the second case of the literature. ${ }^{12}$ Later, Smith et al in 1992 presented a retrospective series of 22 patients with OPLL, 7 of whom had large dural defect. Of the seven, five developed a postoperative pseudomeningocele. ${ }^{13}$ Their therapeutic measures included observation, lumbar subarachnoid shunt and if refractory repair with fascia or artificial dural patch at reoperation. Thereafter, Fountas et al reported their case in $2005 .{ }^{14}$ Since then only a few cases of anterior cervical pseudomeningocele as the sequel of anterior cervical surgical procedures for discectomy or corpectomy have been published so far..$^{15-17}$

Surprisingly, all these reported cases were acute ones and in careful review of the literature, we could not find even a single case of chronic spinal pseudomeningocele following anterior spinal surgeries.

Herein a middle age woman, who had undergone combined anterior-posterior surgery because of cervical spondylotic myelopathy is presented. Postoperatively, although the patient's neurological status showed marked improvement. But, she noticed formation of a soft lump on the anterior aspect of her neck 6 months after surgery This was diagnosed to be chronic cervical pseudomeningocele. Because, she refused surgery, periodic observation was suggested. Hopefully, in two years observation, the mass has showed no change in size.

To our knowledge, this is the first example of chronic anterior cervical pseudomeningocele presented in the literature. Furthermore, the natural course of the chronic cases might be explained where at 2-year follow-up it remained of the same size.

\section{Case Report}

This 49-year- old woman was referred for a mass that had appeared 6 months after successful combined anterior and posterior surgery for a cervical spondylotic myelopathy. According to her surgeon, she has mild quadriparesis on admission with hyperactive reflexes and bilateral extensor planter responses. Accordingly, her MJOA had been 14 before surgery. On admission to our institute, there was a soft mass measuring $6 \mathrm{X} 7 \mathrm{Cm}$ in diameter, on the right anterior aspect of the neck (Figure 1). The mass was soft and no bruit could be heard on ausculation. Her neurological examination compared to the report was promising with only paresthesia in the feet and hyperactive reflexes remained. X-ray revealed cervical corpectomy from $\mathrm{C} 4$ to $\mathrm{C} 6$ where the site was replaced by a titanium cage of appropriate size being secured in place by a long plate. Moreover, a round shadow was seen in anteroinferior aspect of the neck on the right side (Figure 2). In addition, posterior laminectomy and posterior screw rod fixation were seen.

MRI revealed a low intensity mass comparable with CSF intensity which started from the site of injury toward the skin , In T2-weight images, the mass was hyperintense comparable with CSF collection (Figure 3). Therefore, the diagnosis of chronic pseudomeningocele was made. Subsequently, de-

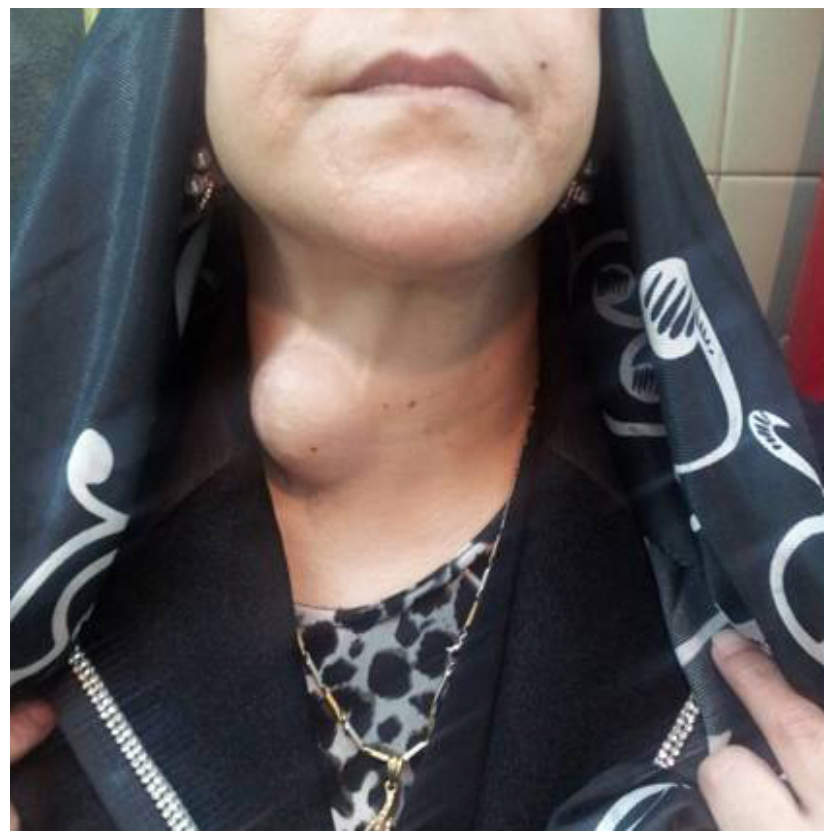

Fig. 1. The patient with a round mass on the right inferior side of the neck. 
layed slices, 2 hours after CT metrizamide myelography clearly showed a pseudomeningocele originating from the spinal subarachnoid space, although the neck of the pathology could not be determined precisely (Figure 4). Since reoperation and repair was a demanding procedure, cystoperitoneal shunt was suggested, but, she refused surgery. Therefore, periodic observation was proposed. Hopefully, at two years follow-up, the mass has remained of the same size.

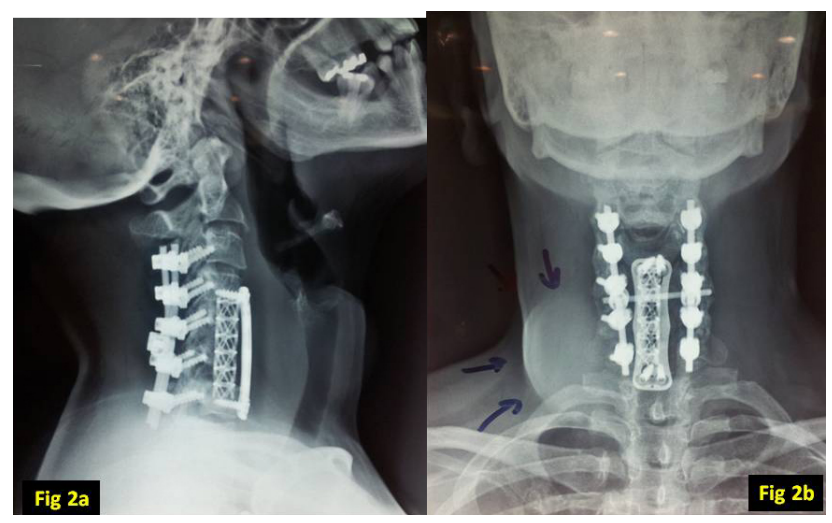

Fig. 2. Cervical plain radiographs: (a) Lateral X-ray shows a titanium mesh at the site of corpectomy secure by a plate as well as lateral mass screw-rod fixation.(b) AP X-ray besides showing 360 surgery, a round shadow is seen in the antreroinferior as pect of the neck on the right side.

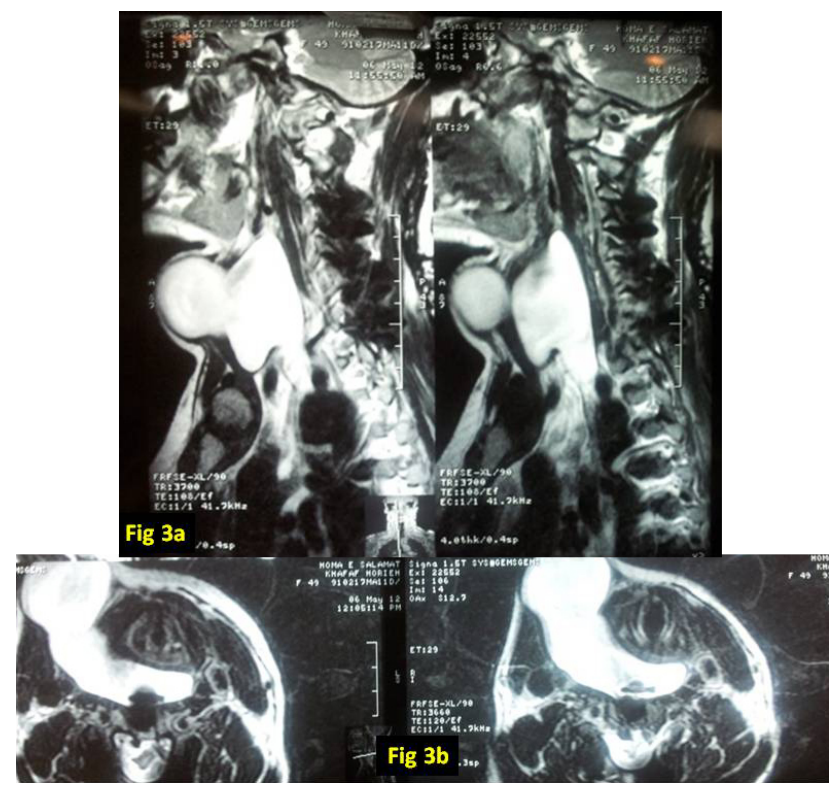

Fig. 3. Cervical MRI: (a) T2-weighted sagittal images demonstrating a hyperintense mass from the anterior aspect of the cervical spine with extension to subcutaneous as mass. (b) T2-weighted axial view depicting the same scenario.

\section{Discussion}

Dural tears are among the most serious complications of anterior cervical procedures. ${ }^{18-22}$ Dural tears are more seen in anterior cervical corpectomy (AC$\mathrm{CF}$ ) rather than anterior cervical disc fusion and in the former group more common in ossified posterior longitudinal ligament(OPLL) than cervical spondylotic stenosis. ${ }^{13}$ May authors have reported variable incidence of this complication in their studies. ${ }^{11,19-21}$ In their large clinical series, Tew and Mayfield occurrence of dural tears has been mentioned. Although they did not report the exact number of cases, they did report that the dural opening was covered by a fascial graft with no subsequent CSF leak. ${ }^{19}$ Similarly, Graham reported occurrence of CSF leak secondary to accidental dural tear, without reporting the actual incidence of it. ${ }^{20}$ In another large series (450 patients) of anterior cervical discectomy, Bertalnaffy and Eggert encountered a dural tear in 8 cases or $1.8 \%$ of their cases. ${ }^{11}$ Dural tear was $0.5 \%$ in Fountas et al series of 1015 patients who had undergone anterior cervical discectomy with and without fusion. ${ }^{21}$ Incidence of cerebrospinal leak following anterior cervical spine surgeries in a series of 1994 patients reported by Hannallah et al, was $0.1 \%$ and it was shown that leak is more common in primary corpectomy, revision corpectomy and in OPLL rather than anterior cervical discectomy and fusion. ${ }^{22}$

Dural defects, irrespective of the means by which they occur after anterior discectomy or corpectomy which are not properly repaired, permit CSF egress to the surrounding tissues through a fistula ${ }^{23}$ When the CSF pulse pressure exceeds the interstitial pressure of the surrounding tissue, a pseudomeningocele can develop in anterior compartment of the neck.

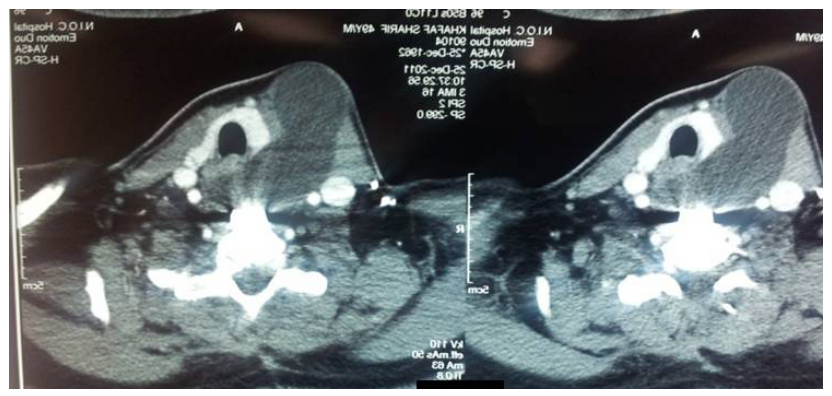

Fig. 4. Cervical axial CT. Metrizamide Image which shows a large pseudomeningocele in the anterior aspect of the neck. 
Therefore, cervical pseudomeningocele can be classified into 2 types: acute and chronic ones with consideration of the time of clinical presentation. The time necessary for formation of the pseudomeningocele depends on the size of dural defect, pressure of the spinal fluid and resistance of the surrounding soft tissues. Acute ones are actually simple CSF collection with faint fibrous reactive wall, in the anterior aspect of the neck on the side of incision between the strenocleidomastoid muscle and carotid jugular complex on the lateral side and esophago-tracheal complex on the medial side. ${ }^{13,14}$ Acute ones are as the result of large dural defects where the fistula encourages high unidirectional CSF flow (ball valve) and rapid expansion of the pseudomeningocele with each cardiac cycle.

If the all layers of the incision have been closed tightly, cerebrospinal fluid collection may result in compression of adjacent structures including esophagus trachea and even the spinal cord. If the layers of the cervical incision are not closed tightly, CSF will leak through the surgical incision. ${ }^{11-17}$

However, removal of the osteophytes in cervical spondylotic myelopathy may result in micro tears which are not immediately evident. But can lead to low flow cerebrospinal fluid fistula with very gradual expansion and ultimately chronic formation of a pseudomeningocele as was demonstrated in the present case.

In order to prevent CSF leak and subsequent formation of fistula and pseudomeningocele, mostly advocate insertion of a lumbar drain in the patients with dural tears, along with coverage of the dural opening with a fascial graft. ${ }^{24,25}$ Post operative lumbar subarachnoid drainage should be at the rate of $8-12 \mathrm{~mL} /$ $\mathrm{h}$ and be kept in place for 5 days, but both in discectomy and corpectomy lumbar subarachnoid drainage should be modified on the base of clinical response. ${ }^{24,25}$ Drainage for longer period might increase the risk of infection. Over-drainage may result in intracranial hemorrhage mainly subdural hematoma. ${ }^{26}$

Fibrin glue or other sealants can be used as the final step. In corpectomy the dural tears might be proper for microscopic suturing, both primary closure or ap- plication artificial dural patch are recommended with subsequent use of a thin layer of free fat graft mixed with fibrin glue or different sealing materials are recommended. ${ }^{23}$

Clinically, low flow anterior cervical pseudomeningoceles might remain asymptomatic being presented with postural headache or local pain.

Pseudomeningocele formation in high flow cerebrospinal fluid fistula can result in compression of the surrounding structures, usually causing respiratory distress, marked dysphagia and even aggravation of previous spinal cord signs and symptoms. Postural headache which is actually due to reduced intracranial pressure is another feature of cervical pseudomeningoceles. High flow pseudomeningoceles might be presented as fluctuant trans-illuminant neck mass that enlarges with coughing and sneezing . Furthermore, the literature contains rare reports of more serious complications of pseudomeningocele, including herniation of the spinal cord into the pseudocyst causing neurologic decline. ${ }^{10}$

In CT Metrizamide myelogram, delayed images can show collections of semi-opaque material in the anterior aspect of the neck on the side of the surgery. The site of connection of the pseudomeningocele to the techa might be seen. ${ }^{1-3}$

In MRI, both in T1 and T2 -weighted images, pseudomeningocele is demonstrated as a cyst containing a fluid with low intensity in T1 weight and with high intensity in T2-weighted MRI, comparable with the density of the cerebrospinal fluid. The cyst and its connection with intrathecal subarachnoid space might be seen. ${ }^{9,10,15}$

Once formation of a pseudomeningocele is confirmed a therapeutic decision making is necessary. However, optimal management is dependent on many factors, including sac size, location, clinical picture and the time of diagnosis. For example, small pseudomeningoceles with minimal symptoms, being identified incidentally require no treatment. The conservative management in asymptomatic patients has been accepted because even large pseudomeningoceles may scar down" and resolves over time. 
In high flow acute pseudomeningoceles with protrusion in the neck or CSF leakage, compression of the mass with pressure dressing around the neck may result in complete resolution of the postural headaches and decreased fluctuation of the mass. For complete resolution of the pseudomeningocele, the pressure dressing has been advocated to be used up to 12 weeks. Extrinsic compression might promote scarring by increasing the interstitial pressure of the surrounding tissues.

Along with extrinsic pressure, symptomatic pseudomeningoceles can be effectively managed with continuous lumbar drainage. ${ }^{24,25}$

If these modes remain refractory, revision surgery is indicated, although re-exploration poses a challenge in corpectomy cases. The mainstay of treatment will be closure of the dural defect. The cyst should be incised and the dural defect which is mostly located at the bottom of the scene can be identified. If the defect is small it can be closed with interrupted sutures. But, If the dural defect is large, fascia or artificial dural patch fortified with fibrin glue can be used. ${ }^{1-3}$ Occasionally, dural repair might be impossible despite removal of the plate and the cage. In this circumstances, cystoperitoneal shunt might be the only solution. ${ }^{15}$

In chronic case, the small ones which are identified incidentally should be left untreated. although periodic MRI follow-up for evaluation of the size of the cyst is recommended. However, revision surgery in those cysts with high flow and large volume after anterior discectomy and fusion is indicated where in low flow chronic pseudomeningoceles developing after corpectomy and fusion as was observed in our case, re-exploration will be a demanding procedure. Therefore, in such cases CSF diversion with primary cystoperitoneal shunt seems justified.

In summary, It seems that the current case is the first example of remote presentation of a cervical pseudomeningocele after an anterior cervical procedure. However, our purpose in this report is not only stressing on the rarity of the event but we want to show the natural course of chronic cases. Due to the paucity of the cases in the literature, the natural his- tory of this pathology is not clearly understood. However, the current case might reflect the selflimited nature of the chronic cases where a balance between the CSF accumulation and its possible resorption by the inner layer of the cyst might be the mechanism. Another mechanism which result in cyst size stability might be the equality of the pressure gradient of the interstitial tissue and intra-cystic pressure.

Further studies and more cases presented in the future might clear the cause of the stability in chronic iatrogenic pseudomeningoceles with time.

\section{Acknowledgement}

The authors appreciate Miss Mona Karimi and Mr. Alireza Mojtahed for their efforts in PAMIM research Center.

\section{References}

1. Hawk MW, Kim KD: Review of spinal pseudomeningoceles and cerebrospinal fluid fistulas. Neurosurg Focus 2000, 9:e5.

2. Couture D, Branch CL Jr. Spinal pseudomeningoceles and cerebrospinal fluid fistulas. Neurosurg Focus. 2003;15(6):E6.

3. Rahimizadeh A, Kaghazchi M, Rahimizadeh A.post-laminectomy pseudomeningocele: Report of three cases and review of the literature. World Spinal Column J( WScJ)2014;4:103-108.

4. Goodman S, Gregorius FK. Cervical pseudomeningocele after laminectomy as a cause of progressive myelopathy. Bull Los Angeles Neurol Soc1974;39:121-127.

5. Burres KP, Conley FK. Progressive neurological dysfunction secondary to postoperative cervical pseudomeningocele in a C-4 quadriplegic. Case report. J Neurosurg 1978;48:289-91.

6. Helle TL, Conley FK. Postoperative cervical pseudomeningocele as a cause of delayed myelopathy. Neurosurgery 1981;9:314-316.

7. Hanakita J, Kinuta Y, Suzuki T. Spinal cord compression due to postoperative cervical pseudomeningocele. Neurosurgery 1985;17: 317-319. 8. Maiuri F, Carriero G, Giamundo A, Donati P, 
Gambardella A. Postoperative cervical pseudomeningocele. Neurochirurgia 1988;31:29-31. 9. Morgan SL, Krishna V, Varma AK.Cervical pseudomeningocele as a cause of neurological decline after posterior cervical spine surgery. Neurol India. 2012;60:256-7.

10. Moriyama $T$, Tachbana $T$, Maruo $K$, Inoue $S$, Okada F, Yoshiya S. Postoperative spinal cord herniation with pseudomeningocele in the cervical spine: a case report. The Spine J2013;13:e41-45.

11. Bertalnaffy H, Eggert HR. Complications of anterior cervical discectomy without fusion in 450 consecutive patients. Acta Neurochir 1989;99:41.

12. Horowitz SW, Azar-Kia B, Fine M. Postoperative cervical pseudomeningocele. AJNR Am J Neuroradiol. 1990;11:784.

13. Smith MD, Bolesta MJ, Levinthal M, et al. Postoperative cerebrospinal fluid fistula associated with erosion of the dura. J Bone Joint Surg

Am.1992;74:270-277.

14. Fountas KN, Kapsalaki EZ, Johnston KW. Cerebrospinal fluid fistula secondary to dural tear in anterior cervical discectomy and fusion. Spine 2005; 30:E227.

15. Shane A, Kanwaldeep S. Cervical-peritoneal shunt placement for postoperative cervical pseudomeningocele; case report. J Spinal Disord Tech 2005,18:290-292.

16. Weng Y J, Cheng CC, Yen-Yao Li YY, Huang TJ, Hsu RW Management of giant pseudomeningoceles after spinal surgery R W, BMC Musculoskeletal Disorders 2010, 11:53.

17. Barazi SA, D'Urso PI, Thomas NW.

Pseudomeningocele after anterior cervical discectomy and fusion: Case report. Cent Eur Neurosurg 2012; 73: P050.

18. Luszczyk MJ, Blaisdell GY, Wiater BP, Bellabarba C, Chapman JR, Agel JA, Bransford RJ. Traumatic dural tears: what do we know and are they a problem? Spine J. 2014 Jan;14:49-56.

19. Tew JM, Mayfield FH. Complications of surgery of the anterior cervical spine. Clin Neurosurg 1976;23:424-34.

20. Graham JJ. Complications of cervical spine surgery: A five-year report on a survey of the mem- bership of the Cervical Spine Research Society by the morbidity and mortality committee. Spine 1989;14:1046-50.

21. Fountas K N, Kapsalaki E Z, Nikolakakos L G, Smisson H F, Johnston KW, Grigorian A A, Lee G P, Robinson JS. Anterior cervical discectomy and fusion associated complication. Spine 2007;32:2310-2317.

22. Hannallah D, Lee J, Khan M, et al. Cerebrospinal fluid leaks following cervical spine surgery. J Bone Joint Surg Am 2008;90:1101-5.

23. Epstein NE, Hollingsworth R: Anterior cervical micro-dural repair of cerebrospinal fluid fistula after surgery for ossification of the posterior longitudinal ligament. Technical note. Surg Neurol 1999;52:511-514.

24. McCallum J, Maroon JC, Jannetta PJ. Treatment of postoperative cerebrospinal fluid fistulas by subarachnoid drainage. J Neurosurg. 1975; 42:

434-437.

25. Kitchel SH, Eismont FJ, Green BA. Closed subarachnoid drainage for management of cerebrospinal fluid leakage after an operation on the spine. J Bone Joint Surg Am. 1989; 71: 984-987.

26. Sciubba D, Kretzer R,Wang P. Acute intracranial subdural hematoma following a lumbar CSF leak caused by spine surgery. Spine 2005; 30: E730-2.

\section{Disclosures \& COI}

The authors have no conflict of interest concerning the materials or methods used in this study or the findings specified in this paper.

\section{Corresponding Author}

Dr Abolfazl Rahimizadeh. Pars Hospital, 67 Keshawarz Blvd, 1415911, Tehran, Iran. a_rahimizadeh@hotmail.com.

Published 17 October 2016.

This manuscript is generously published free of charge by ISASS, the International Society for the Advancement of Spine Surgery. Copyright @ 2016 ISASS. To see more or order reprints or permissions, see http://ijssurgery.com. 